\title{
Degradation and adsorption of tebuconazole and tribenuron-methyl in wheat soil, alone and in combination
}

\author{
Feifei Wang ${ }^{1}$, Zhi Wang ${ }^{1}$, Baohua Zhang ${ }^{1}$, and Qingming Zhang ${ }^{2 *}$
}

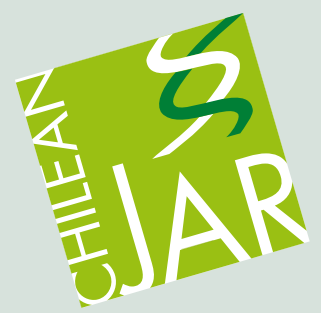

\section{ABSTRACT}

In practice, pesticides are usually simultaneously applied or one after another for crop protection. This often leads to a coexistence of pesticide mixtures in soil. One of the most important processes influencing the behavior of a pesticide in the environment is its degradation and adsorption in soil. Thus, the degradation and adsorption behaviors of tebuconazole (TEB) and tribenuron-methyl (TBM) alone and combined application in wheat soil (pH 7.28) were studied. The concentrations of TEB and TBM in soil were determined using a quick, easy, cheap, efficient, rugged and safe method (QuEChERS) with ultrahigh-performance liquid chromatography tandem mass spectrometry (UHPLC-MS/MS). Results showed that TEB has longer half-lives compared with TBM in the tested soils when they were applied individually. The degradation of TEB was markedly affected by concentration and soil microorganisms. In the non-sterilized soil, half-lives of 0.8 and $80 \mathrm{mg} \mathrm{kg}^{-1}$ TEB were 16.4 and $69.3 \mathrm{~d}$, respectively, and half-lives of 0.8 and $80 \mathrm{mg} \mathrm{kg}^{-1}$ TEB were 20.4 and $73.5 \mathrm{~d}$ in the sterilized soil, respectively. The degradation of TBM was not affected by TEB in both soils; however, TBM could reduce the degradation of TEB. Compared to TEB alone, the rates of degradation of $80 \mathrm{mg} \mathrm{kg}^{-1}$ TEB in presence of $32 \mathrm{mg} \mathrm{kg}^{-1} \mathrm{TBM}$ were reduced $15.9 \%$ and $18.2 \%$ in non-sterilized and sterilized soils, respectively. Soil adsorption affinity of TEB was significantly higher than TBM. When used combined, adsorption capacity of TEB was not affected by TBM. However, the adsorption of TBM was obviously inhibited in presence of TEB.

Key words: Adsorption, combined pollution, degradation, tebuconazole, tribenuron-methyl.

${ }^{1}$ Qingdao Agricultural University, College of Chemistry and Pharmaceutical Sciences, 266109, Qingdao, China.

${ }^{2}$ Qingdao Agricultural University, College of Plant Health and Medicine, 266109, Qingdao, China.

*Corresponding author (zhangqingminghf@163.com).

Received: 24 April 2017.

Accepted: 1 August 2017

doi:10.4067/S0718-58392017000300281

\section{INTRODUCTION}

In agricultural production, pesticides application has been one of an indispensable way to control different types of disease, insect pest, and weeds. However, environmental problems such as water and soil pollution occurred due to high frequency or abuse of pesticides. At present, most studies mainly have focused on the environmental fate of single pesticide compound and its environment effect. However, in practice, different pesticides are usually applied simultaneously or one after another for protecting the crop from damage. This pesticide application can often result in a combined contamination of pesticide residues in the soil environment (Swarcewicz and Gregorczyk, 2012). Degradation and adsorption are two important behaviors of pesticides in soil, which are directly related to how long the pesticides remain in the soil and how seriously the pesticide affect soil environment (Arias-Estévez et al., 2008). Studies showed that degradation and adsorption are governed by several factors such as differences of soil constituents and pesticide properties (Spark and Swift, 2002; Liu et al., 2010). Due to the difference of pesticide physical-chemical properties, degradation and adsorption of individual pesticide may be different from other pesticides in a given soil. For example, White et al. (2010) found that fungicide chlorothalonil could significantly suppress the degradation of herbicide metolachlor in soil, and inhibition rate is up to two times. Swarcewicz and Gregorczyk (2012) demonstrated that fungicide mancozeb and mixture with thiamethoxam could significantly inhibit the degradation of herbicide pendimethalin, but metribuzin did not affect the behavior of pendimethalin in soil. Therefore, it is necessary to compare and analyze the behaviors of individual pesticides and combined use in soil.

Tebuconazole (TEB) [(RS)-1-p-chlorophenyl-4,4-dimethyl3-(1H-1,2,4-triazol-1-ylmethyl)pentan-3-ol] is a broad-spectrum triazole fungicide, which is widely used to control soil-borne and foliar fungal pathogens in many crop plants. Previous studies have demonstrated that TEB can reach soil by falling or other ways and has a relative longer half-life (49-610 d), and thus posing a risk to soil ecological environment (Strickland et al., 2004; Komárek et al., 2010; Muñoz-Leoz et al., 2011). Tribenuron-methyl (TBM) [methyl 2-[4-methoxy-6-methyl1,3,5-triazin-2-yl(methyl)carbamoylsulfamoyl]benzoate] is a sulfonylurea herbicide and is widely used for controlling weed worldwide. Although TBM is regarded to be highly efficient at low dosage, it high phytotoxicity and potential pollution to soil and groundwater has been attracting extensive concern (Kotoula- 
Syka et al., 1993; Battaglin et al., 2000; Olszyk et al., 2010; Mehdizadeh et al., 2016). Wheat (Triticum aestivum L.) is one of the most important food crops worldwide, its yield and quality is very crucial to meet with the increasing population. To overcome this problem, pesticide application has been an important way to improve wheat yield. TEB and TBM are two commonly used pesticides in wheat field, and they play an important role in controlling diseases and weeds (Homdork et al., 2000; Mukherjee et al., 2015). Besides, the dissipation studies of TEB and TBM in wheat and soil have been widely investigated in previous couple of years. However, no other studies are available regarding the degradation and adsorption of TEB and TBM coexisted in a given wheat soil.

Therefore, the objective of the present experiment was to investigate degradation and adsorption of TEB and TBM alone and combined, and to compare the differences between two pesticides in a given wheat soil.

\section{MATERIALS AND METHODS}

\section{Pesticides, reagents, and soil}

Tebuconazole (98\% purity) and TBM (96.5\% purity) were provided by the Jingbo Agrochemicals Technology (Boxing, Shandong, China). Acetonitrile and methanol (HPLC grade) were purchased from Tianjin Concord Technology (Tianjin, China). Acetone, sodium chloride and anhydrous magnesium sulfate are of analytical grade and purchased from Tianjin Yongda Chemical Reagent (Tianjin, China). Primary secondary amine (PSA, 40-60 $\mu \mathrm{m}$ ) and graphitized carbon black (GCB, 40-60 $\mu \mathrm{m}$ ) were purchased from Supelco (Sigma-Aldrich, St. Louis, Missouri, USA). Stock standard solutions of $1000 \mathrm{mg} \mathrm{L}^{-1}$ TEB and TBM were prepared in acetonitrile, and the required working standard solutions were freshly prepared by appropriate dilution of the stock solution. All of the solutions were stored at $4{ }^{\circ} \mathrm{C}$ before using.

The soil (top 0-15 cm) used was collected from a wheat field at modern agricultural technology park of Qingdao Agricultural University, an area with no history of TEB and TBM application in the past 5 yr. It was characterized as clay loam (57\% sand, $23 \%$ silt, and $20 \%$ clay). This soil had $3.75 \%$ organic matter, $13.28 \mathrm{cmol} \mathrm{kg}^{-1}$ cation exchange capacity, and $\mathrm{pH} 7.28$. The collected soil was partially airdried overnight and sieved to pass a 2-mm mesh, and stored at $4{ }^{\circ} \mathrm{C}$ to keep moisture for maintaining biological activity until preparation of the contamination.

\section{Degradation studies}

Degradation of TEB and TBM alone and combined was studied in two different substrates: sterilized soil and nonsterilized soil. Soil was sterilized by autoclaving at $120^{\circ} \mathrm{C}$ for $30 \mathrm{~min}$. In order to maintain soil sterility, the sterile soil was immediately transferred to an aseptic chamber prior to pesticide application. In individual pesticide pollution, two dose levels were applied: a low dose $\left(0.8 \mathrm{mg}^{\mathrm{TEB}} \mathrm{kg}^{-1}\right.$ and $0.32 \mathrm{mg} \mathrm{TBM} \mathrm{kg}{ }^{-1}$ ) represents the recommended dosage, and a high dose (80 mg TEB kg-1 and $32 \mathrm{mg} \mathrm{TBM} \mathrm{kg}^{-1}$ ) represents a spillage situation. Four treatments $(0.8 \mathrm{mg}$ TEB $\mathrm{kg}^{-1}+0.32 \mathrm{mg}$ TBM kg${ }^{-1}, 0.8 \mathrm{mg}$ TEB kg${ }^{-1}+32 \mathrm{mg} \mathrm{TBM}$ $\mathrm{kg}^{-1}, 80 \mathrm{mg}$ TEB kg ${ }^{-1}+0.32 \mathrm{mg} \mathrm{TBM} \mathrm{kg}^{-1}$, and $80 \mathrm{mg}$ TEB $\mathrm{kg}^{-1}+32 \mathrm{mg} \mathrm{TBM} \mathrm{kg}{ }^{-1}$ ) were studied in the two pesticides combined pollution. The mixing of pesticide and soil was performed according to the method described by Wang et al. (2016). Spiked soil samples (100 g) were transferred to a $200-\mathrm{mL}$ brown glass bottle and covered with perforated polypropylene sheets. Three replicate samples per treatment were prepared. All samples were incubated at $25^{\circ} \mathrm{C}$ in the dark, and the moisture content of each soil sample was adjusted to $40 \%$ of water-holding capacity. Subsamples $(5 \mathrm{~g})$ were randomly removed from each treatment on 0,1 , $3,7,14,21,30,60$, and $90 \mathrm{~d}$ and then stored at $-20^{\circ} \mathrm{C}$ until analysis.

\section{Adsorption study}

According to the result of preliminary experiment, concentrations of TEB and TBM were set as $2.5 \mathrm{mg} \mathrm{kg}^{-1}$. The procedure was performed using the standard batch equilibration method refer to Organization for Economic Co-operation and Development (OECD) guideline (No, 2000). All pesticides were dissolved in a $0.01 \mathrm{M}$ calcium chloride. Ten milliliters of pesticide solution were added to $5 \mathrm{~g}$ soil in $50 \mathrm{~mL}$ of centrifuge tubes. The tubes were placed in an orbiter shaker controlled to $25^{\circ} \mathrm{C}$ and agitated over different periods of time $(0.5,1,2,3,4,12,16,20,24 \mathrm{~h}$, respectively). All adsorption experiments were conducted in triplicate. After shaking, the tubes were centrifuged at $4000 \mathrm{rpm}$ for $10 \mathrm{~min}$, and the suspensions were removed for further purification.

\section{Pesticide residue determination}

The quick, easy, cheap, efficient, rugged, and safe method (QuEChERS) was used to extract and separate TEB and TBM in the soil. Briefly, for degradation experiment, $2 \mathrm{~g}$ soil were weighed into to a $10 \mathrm{~mL}$ polytetrafluoroethylene (PTFE) centrifuge tube, and then $5 \mathrm{~mL}$ acetonitrile were added into it. The sample was vortexed for $2 \mathrm{~min}$ at highest speed, and then 1000 $\mathrm{mg}$ magnesium sulfate anhydrous was added into the sample tube. The tube was then vortexed for $2 \mathrm{~min}$ at highest speed followed by centrifugation at $4000 \mathrm{rpm}$ for $10 \mathrm{~min}$. The $3-\mathrm{mL}$ acetonitrile supernatant was transferred to a $10 \mathrm{~mL}$ PTFE centrifuge tube containing $30 \mathrm{mg}$ PSA, $20 \mathrm{mg} \mathrm{GCB}, 1000 \mathrm{mg}$ magnesium sulfate anhydrous, and $200 \mathrm{mg}$ sodium chloride. The tube was firstly vortexed for approximately $1 \mathrm{~min}$, and then centrifuged at $4000 \mathrm{rpm}$ for $10 \mathrm{~min}$. An aliquot of $1 \mathrm{~mL}$ supernatant was filtered into a $1.5 \mathrm{~mL}$ glass auto sampler vial with a $0.22 \mu \mathrm{m}$ pore membrane filter for ultrahigh-performance liquid chromatography-tandem mass spectrometry (UHPLC-MS/MS) analysis. For adsorption experiment, a 3-mL suspension was transferred to a 10 $\mathrm{mL}$ PTFE centrifuge tube and the rest of the steps were the same as described above for degradation experiment. 
The concentrations of TEB and TBM were determined by an Agilent 1290 Infinity/6460 UHPLC/MS/MS instrument (Agilent, Santa Clara, California, USA). The separation of TEB and TBM was achieved on an Agilent Poroshell 120 EC-C18 column $(75 \mathrm{~mm} \times 2.1 \mathrm{~mm} \times 2.7 \mu \mathrm{m})$ maintained at $35{ }^{\circ} \mathrm{C}$. The mobile phase was methanol:0.1\% aqueous formic acid $(60: 40, \mathrm{v} / \mathrm{v})$. The injection volume was $5 \mu \mathrm{L}$ and run time was $5.5 \mathrm{~min}$. Mass spectrometric detection was operated in positive multiple reaction monitoring (MRM) mode with an electrospray ionization (ESI) source. Nitrogen was used for both nebulizer and collision gas. The temperature of gas was $350{ }^{\circ} \mathrm{C}$ with $8.0 \mathrm{~L} \mathrm{~min}^{-1}$ flow rate, and the nebulizing gas pressure was $25 \mathrm{psi}$. The monitored ions were $\mathrm{m} / \mathrm{z} 308$ and $\mathrm{m} / \mathrm{z} 70.2$ for TEB, m/z 396.2 and $\mathrm{m} / \mathrm{z} 155.2$ for TBM, respectively. The retention times of TEB and TBM were 2.85 and $2.24 \mathrm{~min}$, respectively.

\section{Statistical analysis}

Statistical analysis was performed using SPSS 18.0 software (IBM Corporation, Armonk, New York, USA). All data were analyzed using one-way ANOVA. The Dunnett's t-test $(P<0.05)$ was used to compare differences between treatments at a same sampling time. The degradation of two pesticides was fitted to first-order exponential decay equation. Moreover, the equations $\left(C_{t}=C_{0} e^{-k t}\right.$ and $t_{1 / 2}=\ln 2 /$ $\mathrm{k}$, where $\mathrm{C}_{\mathrm{t}}$ is the concentration of pesticide at time $\mathrm{t}, \mathrm{C}_{0}$ is the initial concentration, $\mathrm{k}$ is the rate constant, and $\mathrm{t}_{1 / 2}$ is the half-life) were used to calculate the degradation rate constant and half-life.

\section{RESULTS AND DISCUSSION}

\section{Validation of pesticide residue analysis method}

The validation of the extraction method was evaluated in terms of recoveries of TEB and TBM spiked in soils. As shown in Table 1, for all levels of concentration, the average recoveries of TEB and TBM from non-sterilized and sterilized soils were $80.8 \% \sim 87.2 \%$ and $85.2 \% \sim$ $96.3 \%$ with relative standard deviations of $0.4 \% \sim 8.5 \%$ and $2.6 \% \sim 6.4 \%$, respectively, indicating good accuracy and repeatability of the method. The limits of detection (LODs) and limits of quantification (LOQs) of two pesticides were 0.001 and $0.005 \mathrm{mg} \mathrm{kg}^{-1}$ at signal-to-noise ratios of $3: 1$ and 10:1, respectively. These data indicated that the extraction and determination method is satisfactory for analysis of TEB and TBM residue.

Table 1. Recoveries of tebuconazole (TEB) and tribenuronmethyl (TBM) in soil.

\begin{tabular}{lcccccc}
\hline & & \multicolumn{2}{c}{ Non-sterilized soil } & & \multicolumn{2}{c}{ Sterilized soil } \\
\cline { 3 - 3 } Pesticide & $\begin{array}{c}\text { Fortified } \\
\text { level }\end{array}$ & $\begin{array}{c}\text { Average } \\
\text { recovery }\end{array}$ & RSDs & & $\begin{array}{c}\text { Average } \\
\text { recovery }\end{array}$ & RSDs \\
\hline \multirow{2}{*}{ TEB } & $\mathrm{mg} \mathrm{kg}^{-1}$ & $\%$ & $\%$ & & $\%$ \\
& 0.8 & 87.2 & 0.4 & & 88.6 & 6.4 \\
TBM & 80.0 & 83.5 & 6.7 & & 96.3 & 4.5 \\
& 0.32 & 80.8 & 8.5 & & 85.2 & 4.2 \\
& 32.0 & 84.5 & 0.9 & & 86.3 & 2.6 \\
\hline
\end{tabular}

Average of three replicates. RSD: Relative standard deviation.
Degradation of TEB and TBM alone and combined application in soil

Degradation of two pesticides in non-sterilized and sterilized soils followed first-order kinetics (Figure 1). This was illustrated by the higher values of the coefficient of determination $\left(\mathrm{R}^{2}>0.84\right)$, which was obtained through fitting the linear-order kinetics exponential equation to the degradation data (Table 2). For single pesticide, halflives of TEB and TBM at both dose were ranged from 16.4 to $86.9 \mathrm{~d}$ and 3.0 to $3.9 \mathrm{~d}$ in the soil (sterilized or not), respectively. Among them, half-lives for the dissipation of TEB were significantly longer than those for TBM in all the soils studied (Table 2), indicating that TEB is more persistent in the soil and has potentially more serious threatens to soil ecosystem. The results were consistent with those of previous reports, which described that TEB has a relative long persistence but TBM is easily degraded in soil (Strickland et al., 2004; Muñoz-Leoz et al., 2011; Dong et al., 2015). The reason could be attributed the higher octanolwater partition coefficient of TEB $\left(K_{\text {ow }}=5000\right)$ compared with TBM $\left(K_{\text {ow }}=0.36\right)$, which means TEB is more easily bonded with soil. As shown in Table 1, the have-life of TEB at $80 \mathrm{mg} \mathrm{kg}^{-1}$ (above $69 \mathrm{~d}$ ) was significantly longer than that at $0.8 \mathrm{mg} \mathrm{kg}^{-1}$ (about $20 \mathrm{~d}$ ). This indicated that the degradation rate of TEB depends on its concentration in the soil. The present finding agrees with previous reports by Muñoz-Leoz et al. (2011) and Wang et al. (2016), who also observed a significant decrease at degradation rate of high concentrations of TEB in soil. A possible reason may be higher concentrations of TEB could inhibit the degradative activity of soil microorganisms. From the result of the present study, the degradation rate of TEB in nonsterilized soil was faster than sterilized soil (Table 2). This was further evidence that soil indigenous microorganisms indeed play an important role in TEB degradation. This fact is also in line with previous reports, which found that degradation of TEB is mediated mainly by microorganisms in different substrates (Strickland et al., 2004; Sehnem et al., 2009; Muñoz-Leoz et al., 2011; Castillo et al., 2016). In non-sterilized and sterilized soils, the half-lives of TBM were not obvious changes at both spiked levels (Table 2 ), suggesting that TBM degradation is not affected by microorganisms and concentration. This result was in accordance with reports by Andersen et al. (2001), who found TBM mineralization not occurred in natural soil. Collecting the lower $K_{\text {ow }}$ value, this may be attributed to the significant contribution of chemical hydrolysis. Moreover, previous studies have also confirmed that hydrolysis is a main pathway for TBM degradation since it has the functional group, which is susceptible to hydrolytic reaction (Beyer et al., 1987; Andersen et al., 2001).

The rate of TBM dissipation when applied in combination with both concentrations of TEB was unaffected in nonsterilized and sterilized soils (Figure 1). The reason may be that TBM has low $K_{\text {ow }}$ and faster degradation rate in soil. However, the degradation of TEB was suppressed in presence of TBM. This suppression in TEB degradation 
Figure 1. Degradation of tebuconazole (TEB) and tribenuron-methyl (TBM) individual and combined used in non-sterilized (A and B) and sterilized soils (C and D). Each value is the mean of three replicates, and the error bar depicts standard deviation change from the mean.
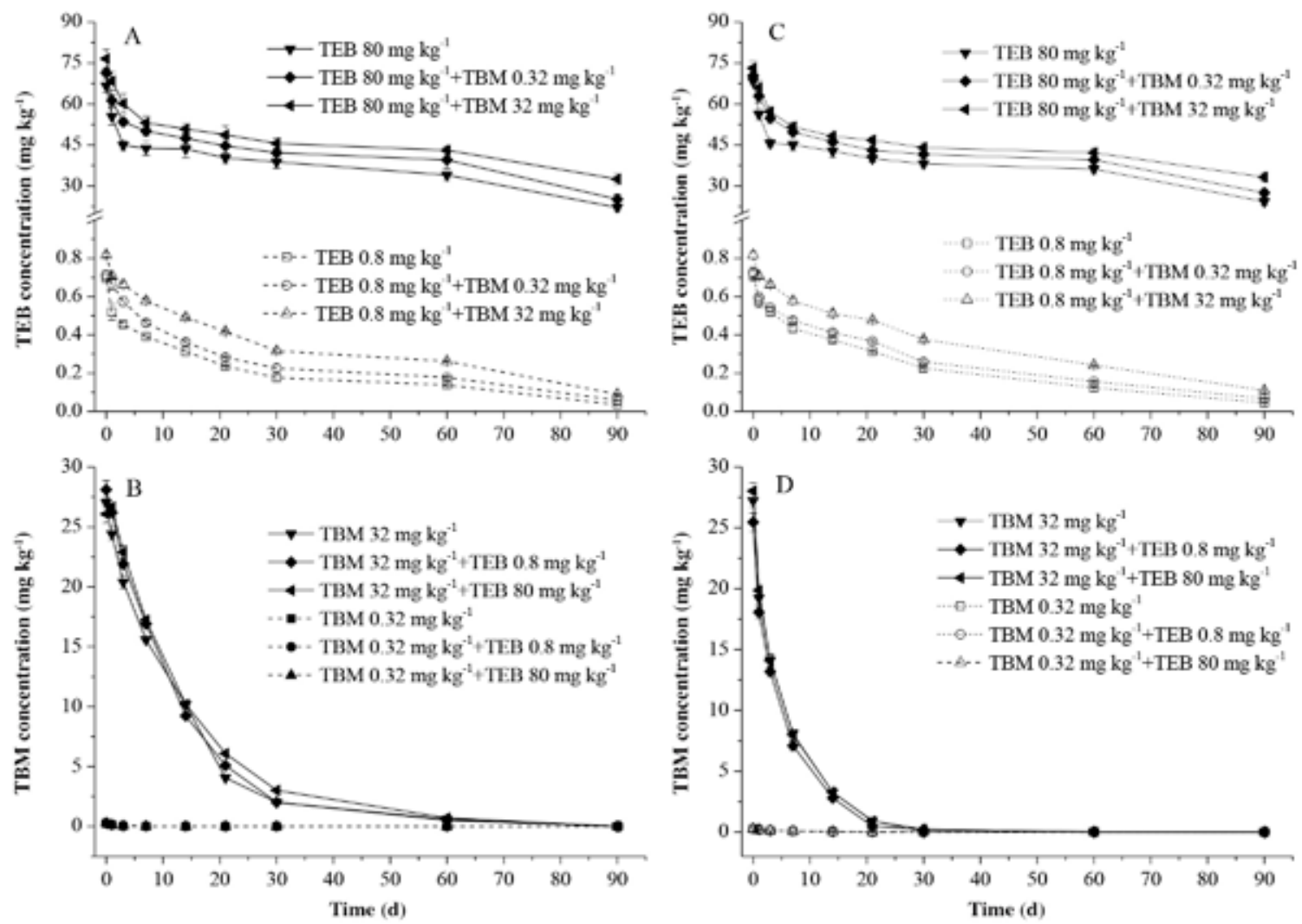

Table 2. Half-life values $\left(T_{1 / 2}\right)$ and other statistical parameters for the degradation of tebuconazole (TEB) and tribenuron-methyl (TBM) individual and combined used in sterilized and non-sterilized soils.

\begin{tabular}{|c|c|c|c|c|c|c|}
\hline \multirow[b]{2}{*}{ Treatments } & \multicolumn{3}{|c|}{ Non-sterilized soil } & \multicolumn{3}{|c|}{ Sterilized soil } \\
\hline & Regression equation & $\mathrm{R}^{2}$ & $\mathrm{~T}_{1 / 2}$ & Regression equation & $\mathrm{R}^{2}$ & $\mathrm{~T}_{1 / 2}$ \\
\hline $\mathrm{mg} \mathrm{kg}^{-1}$ & & & $\mathrm{~d}$ & & & $\mathrm{~d}$ \\
\hline $0.8 \mathrm{TEB}$ & $\mathrm{C}=0.5818 \mathrm{e}^{-0.0423 \mathrm{t}}$ & 0.9109 & $16.4 \mathrm{a}$ & $\mathrm{C}=0.6189 \mathrm{e}^{-0.0339 \mathrm{t}}$ & 0.9504 & $20.4 \mathrm{a}$ \\
\hline $0.8 \mathrm{TEB}+0.32 \mathrm{TBM}$ & $C=0.6673 \mathrm{e}^{-0.00379 t}$ & 0.9521 & $18.3 b$ & $\mathrm{C}=0.6328 \mathrm{e}^{-0.0280 \mathrm{t}}$ & 0.9521 & $24.8 \mathrm{~b}$ \\
\hline $0.8 \mathrm{TEB}+32 \mathrm{TBM}$ & $\mathrm{C}=0.7551 \mathrm{e}^{-0.0302 \mathrm{t}}$ & 0.9029 & $22.9 \mathrm{c}$ & $\mathrm{C}=0.7323 \mathrm{e}^{-0.0214 t}$ & 0.9630 & $32.3 \mathrm{c}$ \\
\hline $80 \mathrm{TEB}$ & $\mathrm{C}=53.5369 \mathrm{e}^{-0.0100 \mathrm{t}}$ & 0.8225 & $69.3 \mathrm{a}$ & $\mathrm{C}=53.9424 \mathrm{e}^{-0.0094 t}$ & 0.8637 & $73.5 \mathrm{a}$ \\
\hline $80 \mathrm{TEB}+0.32 \mathrm{TBM}$ & $\mathrm{C}=59.4170 \mathrm{e}^{-0.0097 \mathrm{t}}$ & 0.8733 & $71.8 \mathrm{a}$ & $\mathrm{C}=59.1229 \mathrm{e}^{-0.0093 \mathrm{t}}$ & 0.8476 & $74.3 \mathrm{a}$ \\
\hline $80 \mathrm{TEB}+32 \mathrm{TBM}$ & $C=64.1583 \mathrm{e}^{-0.0086 t}$ & 0.8282 & $80.3 b$ & $\mathrm{C}=61.1660 \mathrm{e}^{-0.0080 \mathrm{t}}$ & 0.8908 & $86.9 b$ \\
\hline 0.32 TBM & $\mathrm{C}=0.2466 \mathrm{e}^{-0.2242 \mathrm{t}}$ & 0.986 & $3.1 \mathrm{a}$ & $\mathrm{C}=0.2522 \mathrm{e}^{-0.1891 \mathrm{t}}$ & 0.9801 & $3.7 \mathrm{a}$ \\
\hline $0.32 \mathrm{TBM}+0.8 \mathrm{TEB}$ & $\mathrm{C}=0.2494 \mathrm{e}^{-0.2165 \mathrm{t}}$ & 0.9694 & $3.2 \mathrm{a}$ & $\mathrm{C}=0.2437 \mathrm{e}^{-0.1805 t}$ & 0.9822 & $3.8 \mathrm{a}$ \\
\hline $0.32 \mathrm{TBM}+80 \mathrm{TEB}$ & $\mathrm{C}=0.2484 \mathrm{e}^{-0.2299 \mathrm{t}}$ & 0.9767 & $3.0 \mathrm{a}$ & $\mathrm{C}=0.2542 \mathrm{e}^{-0.2076 \mathrm{t}}$ & 0.9864 & $3.3 \mathrm{a}$ \\
\hline 32 TВM & $C=25.2447 \mathrm{e}^{-0.1802 t}$ & 0.9854 & $3.8 \mathrm{a}$ & $\mathrm{C}=25.3998 \mathrm{e}^{-0.1778 \mathrm{t}}$ & 0.9856 & $3.9 \mathrm{a}$ \\
\hline $32 \mathrm{TBM}+0.8 \mathrm{TEB}$ & $\mathrm{C}=24.2582 \mathrm{e}^{-0.1862 \mathrm{t}}$ & 0.9808 & $3.7 \mathrm{a}$ & $\mathrm{C}=23.9499 \mathrm{e}^{-0.1872 \mathrm{t}}$ & 0.9882 & $3.7 \mathrm{a}$ \\
\hline $32 \mathrm{TBM}+80 \mathrm{TEB}$ & $C=26.3540 \mathrm{e}^{-0.1904 t}$ & 0.9858 & $3.6 \mathrm{a}$ & $\mathrm{C}=26.2498 \mathrm{e}^{-0.1865 t}$ & 0.9857 & $3.7 \mathrm{a}$ \\
\hline
\end{tabular}

Different letters of each column of $\mathrm{T}_{1 / 2}$ represent significant difference $(P<0.05)$ at same pesticide concentration.

rate was stronger with the increase of TBM concentration (Figure 1). At $0.8 \mathrm{mg} \mathrm{kg}^{-1}$, in non-sterilized soil, the calculated half-lives of TEB when applied in 0.32 and 32 mg kg${ }^{-1}$ TBM were 18.3 and $22.9 \mathrm{~d}$, increasing $11.6 \%$ and $39.6 \%$ compared to TEB alone, respectively. On the other side, half-lives of $80 \mathrm{mg} \mathrm{kg}^{-1}$ TEB were 71.8 and $80.3 \mathrm{~d}$ in presence of 0.32 and $32 \mathrm{mg} \mathrm{kg}^{-1} \mathrm{TBM}$ in non-sterilized soil, respectively. Compared with TEB alone, degradation rate was also reduced $3.6 \%$ and $15.9 \%$ at both concentration levels, respectively (Table 2). In the sterilized soils, the pattern of TEB degradation in presence of TBM was same to that in the non-sterilized soil. According to the theory of Bielefeldt and Stensel (1999), three potential interactive factors, namely toxicity, competitive and non-competitive inhibition, can result in decreasing degradation rates in combined pollution system. Because TEB and TMB have different chemical structure and were degraded in soils by different mechanisms, competitive inhibition is expected to have less influence in degradation of both pesticides. Therefore, toxicity and non-competitive inhibition of TEB with TBM and its metabolites were presumed to be responsible for the decrease in TEB degradation rate. 
This speculation was in line with previous report by $\mathrm{Li}$ et al. (2008), who thought that above mentioned factors could cause decrease of degradation rates of two different herbicides. However, the specific influence mechanism still need to be further studied.

\section{Adsorption of TEB and TBM alone and combined application in soil}

Until now, many studies on adsorption of TEB and TBM in different soil environment have been reported. These studies revealed that TEB has a moderate adsorption but TBM presents a low adsorption in different soils (Kotoula-Syka et al., 1993; Álvarez-Benedí et al., 1998; Cadková et al., 2013; Papadopoulou et al., 2016). Therefore, the experiment on the adsorption isotherms of both pesticides was not carried out in the present study. In here, we only investigated the adsorption variation of TEB and TBM alone and combined application in the soil. For single pesticide, TEB and TBM showed an initial fast adsorption in the first few hours, and followed by a slower adsorption (Figure 2). The reason may be that soil surface present many adsorption points in the first hours of the adsorption process, thereby increasing the adsorption rates of these two pesticides. With the increasing adsorption, the soil adsorption points were gradually saturated and resulted in a slower adsorption (Bermúdez-Couso et al., 2011). In this study, soil adsorption affinity of TEB was significantly higher than TBM, which is in accordance with mentioned previous studies. Based on the research of Álvarez-Benedí et al. (1998), the low adsorption capacity of TBM should due to this pesticide is predominantly in the anionic form in the soil ( $\mathrm{pH} 7.28)$, and would be repelled by the negatively charged clay particles. For combined use, the soil adsorption affinity of TEB was not affected by TBM, however the adsorption of TBM decreased in soil involved TEB (Figure 2). The reason may be that TEB has higher adsorption affinity and occupied more adsorption points in the soil, and thus lead to the decline of TBM adsorption. Moreover, in presence

Figure 2. Adsorption curve of tebuconazole (TEB, solid line) and tribenuron-methyl (TBM, dash line) individual and combined used in soil.

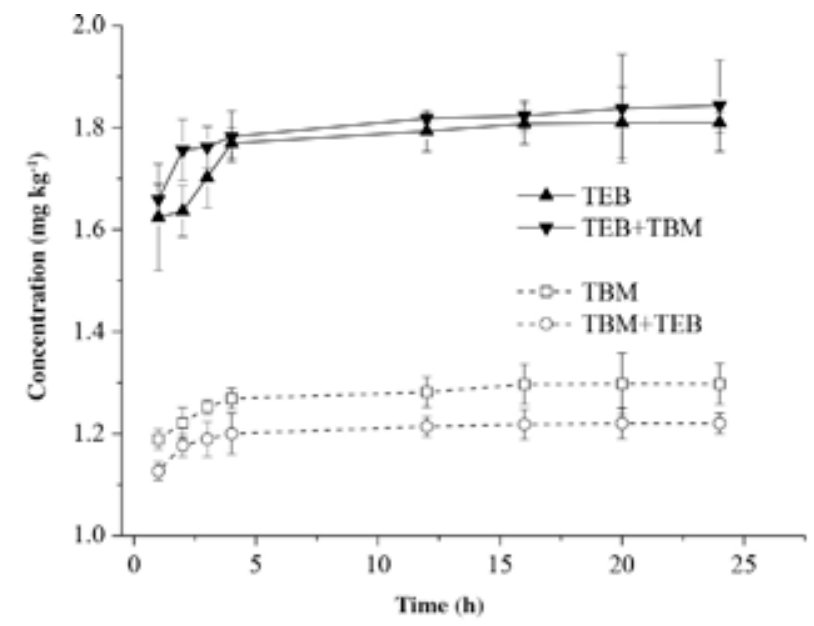

of TEB, the decrease of TBM adsorption rate in the soil environment indicated that combined pollution of TEB and TBM might increase the threat to groundwater resources. It should be noted that our study only investigated the adsorption behavior of TEB and TBM in one soil ( $\mathrm{pH} 7.28$, about neutral). However, previous literature has pointed that $\mathrm{pH}$ plays a crucial role in TEB and TBM adsorption (Riise, 1994; Cadková et al., 2013). Thus, the adsorption behavior of TEB and TBM combined pollution in different soil $\mathrm{pH}$ deserve further studies.

\section{CONCLUSIONS}

In this study, the degradation and adsorption of tebuconazole (TEB) and tribenuron-methyl (TBM) alone and combined were studied in wheat soil. Overall, for single pesticide, degradation of TBM was markedly faster compared with TEB in non-sterilized and sterilized soils. Concentration and soil microorganisms (sterilized or not) cannot affect TBM degradation, but they play an important role in TEB degradation in the soil (showing the higher concentration, sterilized soil, the longer life). For combine used, TBM degradation in presence of TEB was not an obvious change. However, TEB degradation can be slightly inhibited by TBM in both soils. Soil adsorption affinity of TEB was significantly higher than TBM. In presence of TBM, TEB adsorption affinity did not change compared with TEB alone, but the presence of TEB can decrease the adsorption capacity of TBM in the soil.

\section{ACKNOWLEDGEMENTS}

This work was funded by the National Natural Science Foundation of China (41101488), the National Natural Science Foundation of Shandong Province (ZR2016CM11), and the Program of Scientific Innovation for graduate in Qingdao Agricultural University (QYC201520).

\section{REFERENCES}

Álvarez-Benedí, J., Cartón, A., and Fernández, J. 1998. Sorption of tribenuron-methyl, chlorsulfuron, and imazamethabenzmethyl by soils. Journal of Agricultural and Food Chemistry 46:2840-2844.

Andersen, S.M., Hertz, P.B., Holst T., Bossi, R., and Jacobsen, C.S. 2001. Mineralisation studies of 14 C-labelled metsulfuronmethyl, tribenuron-methyl, chlorsulfuron and thifensulfuronmethyl in one Danish soil and groundwater sediment profile. Chemosphere 45:775-782.

Arias-Estévez, M., López-Periago, E., Martínez-Carballo, E., Simal-Gándara, J., Mejuto, J.C., and García-Río, L. 2008. The mobility and degradation of pesticides in soils and the pollution of groundwater resources. Agriculture, Ecosystems \& Environment 123:247-260.

Battaglin, W., Furlong, E., Burkhardt, M., and Peter, C. 2000. Occurrence of sulfonylurea, sulfonamide, imidazolinone, and other herbicides in rivers, reservoirs and ground water in the Midwestern United States, 1998. Science of the Total Environment 248:123-133. 
Bermúdez-Couso, A., Fernández-Calviño, D., Pateiro-Moure, M., Nóvoa-Muñoz, J.C., Simal-Gándara, J., and Arias-Estévez, M. 2011. Adsorption and desorption kinetics of carbofuran in acid soils. Journal of Hazardous Materials 190:159-167.

Beyer, E., Brown, H., and Duffy, M. 1987. Sulfonylurea herbicide soil relations. p. 431-540. Proceedings of the British Crop Protection Conference-Weeds. British Crop Protection Council, London, UK.

Bielefeldt, A., and Stensel, H. 1999. Modeling competitive inhibition effects during biodegradation of BTEX mixtures. Water Research 33:707-714

Cadková, E., Komárek, M., Kaliszová, R., Vanek, A., and Balíková, M. 2013. Tebuconazole sorption in contrasting soil types. Soil and Sediment Contamination 22:404-414.

Castillo, J.M.C., Delgado-Moreno, L., Núñez, R., Nogales, R., and Romero, E. 2016. Enhancing pesticide degradation using indigenous microorganisms isolated under high pesticide load in bioremediation systems with vermicomposts. Bioresource Technology 214:234-241.

Dong, B., Qian, W., and Hu, J. 2015. Dissipation kinetics and residues of florasulam and tribenuron-methyl in wheat ecosystem. Chemosphere 120:486-491.

Homdork, S., Fehrmann, H., and Beck, R. 2000. Effects of field application of tebuconazole on yield, yield components and the mycotoxin content of fusarium-infected wheat grain. Journal of Phytopathology 148:1-6.

Komárek, M., Cadková, E., Chrastný, V., Bordas, F., and Bollinger, J.C. 2010. Contamination of vineyard soils with fungicides: a review of environmental and toxicological aspects. Environment International 36:138-151.

Kotoula-Syka, E., Eleftherohorinos, I., Gagianas, A., and Sficas, A. 1993. Phytotoxicity and persistence of chlorsulfuron, metsulfuron-methyl, triasulfuron and tribenuron-methyl in three soils. Weed Research 33:355-367.

Li, K.B., Cheng, J.T., Wang, X.F., Zhou, Y., and Liu W.P. 2008. Degradation of herbicides atrazine and bentazone applied alone and in combination in soils. Pedosphere 18:265-272.

Liu, Y., Xu, Z., Wu, X., Gui, W., and Zhu, G. 2010. Adsorption and desorption behavior of herbicide diuron on various Chinese cultivated soils. Journal of Hazardous Materials 178:462-468.

Mehdizadeh, M., Alebrahim, M.T., Roushani, M., and Streibig, J.C. 2016. Evaluation of four different crops' sensitivity to sulfosulfuron and tribenuron methyl soil residues. Acta Agriculturae Scandinavica, Section B-Soil \& Plant Science 66:706-713.
Mukherjee, I., Das, T., Kumar, A., Sarkar, B., and Sharma, K. 2015. Behavior and bioefficacy of tribenuron-methyl in wheat (Triticum aestivum L.) under irrigated agro-ecosystem in India. Environmental Monitoring and Assessment 187:1-9.

Muñoz-Leoz, B., Ruiz-Romera, E., Antigüedad, I., and Garbisu, C. 2011. Tebuconazole application decreases soil microbial biomass and activity. Soil Biology and Biochemistry 43:2176-2183.

No, O.T. 2000. 106: Adsorption-desorption using a batch equilibrium method. OECD Guidelines for the Testing of Chemicals 1-45.

Olszyk, D., Pfleeger, T., Lee, E.H., and Plocher, M. 2010. Phytotoxicity assay for seed production using Brassica rapa L. Integrated Environmental Assessment and Management 6:725-734.

Papadopoulou, E.S., Karas, P.A., Nikolaki, S., Storck, V., Ferrari, F., Trevisan, M., et al. 2016. Dissipation and adsorption of isoproturon, tebuconazole, chlorpyrifos and their main transformation products under laboratory and field conditions. Science of the Total Environment 569:86-96.

Riise, G. 1994. Association of tribenuron-methyl with colloidal and particulate materials. Science of the Total Environment 152:91-99.

Sehnem, N.T., Souza-Cruz, P., Peralba, M.D.C.R., and Ayub, M.A.Z. 2009. Biodegradation of tebuconazole by bacteria isolated from contaminated soils. Journal of Environmental Science and Health Part B 45:67-72.

Spark, K., and Swift, R. 2002. Effect of soil composition and dissolved organic matter on pesticide sorption. Science of the Total Environment 298:147-161.

Strickland, T.C., Potter, T.L., and Joo, H. 2004. Tebuconazole dissipation and metabolism in Tifton loamy sand during laboratory incubation. Pest Management Science 60:703-709.

Swarcewicz, M.K., and Gregorczyk, A. 2012. The effects of pesticide mixtures on degradation of pendimethalin in soils. Environmental Monitoring and Assessment 184:3077-3084.

Wang, C., Wang, F., Zhang, Q., and Liang, W. 2016. Individual and combined effects of tebuconazole and carbendazim on soil microbial activity. European Journal of Soil Biology 72:6-13.

White, P.M., Potter, T.L., and Culbreath, A.K. 2010. Fungicide dissipation and impact on metolachlor aerobic soil degradation and soil microbial dynamics. Science of the Total Environment 408:1393-1402. 